\title{
Gallic acid induces apoptosis in A375.S2 human melanoma cells through caspase-dependent and -independent pathways
}

\author{
CHYI LO ${ }^{1,2}$, TUNG-YUAN LAI ${ }^{3,4}$, JEN-HUNG YANG $^{5,6}$, JAI-SING YANG $^{7}$, YI-SHIH MA ${ }^{1,8}$, \\ SHU-WEN WENG ${ }^{1}$, YA-YIN CHEN ${ }^{1,9}$, JAUNG-GENG LIN $^{1}$ and JING-GUNG CHUNG ${ }^{10,11}$
}

\begin{abstract}
Schools of ${ }^{1}$ Chinese Medicine, ${ }^{2}$ Nursing, and ${ }^{3}$ Post-baccalaureate Chinese Medicine; Departments of ${ }^{7}$ Pharmacology, ${ }^{10}$ Biological Science and Technology, China Medical University; Departments of ${ }^{4}$ Chinese Internal Medicine, and ${ }^{9}$ Chinese Medicine, China Medical University Hospital, Taichung 404; ${ }^{5}$ Department of Dermatology, ${ }^{6}$ School of Medicine, Chung Shan Medical University, Taichung 402; ${ }^{8}$ Department of Chinese Medicine, Chang-Hua Hospital, Department of Health, Executive Yuan, Changhua 513; ${ }^{11}$ Department of Biotechnology, Asia University, Wufeng, Taichung 413, Taiwan, R.O.C.
\end{abstract}

Received February 25, 2010; Accepted April 19, 2010

DOI: 10.3892/ijo_00000686

\begin{abstract}
The natural antioxidant gallic acid (GA) has demonstrated a significant inhibition of cell proliferation and induction of apoptosis in a series of cancer cell lines. However, there is no available information to show whether GA induces apoptosis in human skin cancer cells. In the present study, we report GA-induced apoptosis in A375.S2 human melanoma cells. GA affected morphological changes, decreased the percentage of viable cells and induced apoptosis in A375.S2 cells in a dose- and time-dependent manner. Observation of the molecular mechanism of apoptosis in A375.S2 cells showed that GA up-regulated the proapoptotic proteins such as Bax, and induced caspase cascade activity, but down-regulated antiapoptotic proteins such as Bcl-2. GA induced reactive oxygen species (ROS) and intracellular $\mathrm{Ca}^{2+}$ productions and decreased the level of mitochondrial membrane potential $\left(\Delta \Psi_{m}\right)$ in A375.S2 cells in a timedependent manner. GA triggered cytosolic release of apoptotic molecules, cytochrome c, promoted activation of caspase-9 and caspase-3, and ultimately apoptotic cell death. In addition, GA also promoted cytosolic release of apoptosisinducing factor (AIF) and endonuclease G (Endo G). Therefore, GA may also induce apoptosis through a caspaseindependent pathway. Our results suggest that GA might be a
\end{abstract}

Correspondence to: Dr Jaung-Geng Lin, School of Chinese Medicine, China Medical University, No. 91, Hsueh-Shih Road, Taichung 404, Taiwan, R.O.C.

E-mail: jglin@mail.cmu.edu.tw

Dr Jing-Gung Chung, Department of Biological Science and Technology, China Medical University, No. 91, Hsueh-Shih Road, Taichung 404, Taiwan, R.O.C.

E-mail: jgchung@mail.cmu.edu.tw

Key words: gallic acid, apoptosis, endoplasmic reticulum stress, caspase cascade, A375.S2 human melanoma cells potential anticancer compound; however, in depth in vivo studies are needed to elucidate the exact mechanism.

\section{Introduction}

In the world human population, skin cancer causes death (1). The treatment of skin cancer includes surgery, radiation, chemotherapy, or a combination of radiotherapy and chemotherapy, however, the treatment is rather unsatisfactory. Melanoma is highly resistant to conventional chemotherapy and it preferentially metastasize to the brain, lung, liver, and skin (2). It is well-documented that chemoprevention and chemotherapy are the use of pharmacological or natural agents for inhibiting the development, and for cure of cancer. Chemoprevention can prevent a wide variety of cancers in multiple animal models (3) and naturally occurring substances are recognized to be antioxidants and cancer-preventative agents, or even cancer therapy drugs (4).

Gallic acid (3,4,5-trihydroxybenzoic acid, GA), an intermediate component of plant metabolism from the hydrolysis of tannins (5), has been associated with a wide variety of biological actions including antioxidant (6), antibacterial (7), antifungal and antimalarial (8), and antiherpetic action (5). The main interest in GA is related to its antitumoral activity. GA induced apoptosis in human leukemia HL-60RG cells (9), human lung cancer cell lines (10), human stomach cancer KATO III, colon adenocarcinoma COLO 205 cell line (11) and PC12 rat pheochromocytoma cells (12). It was also reported that GA plays an important role in the prevention of malignant transformation (13) and GA prevents amyloid B-induced apoptotic neuronal death by interfering with the increase of $\mathrm{Ca}^{2+}$ levels and then by inhibiting glutamate release and generation of ROS (14). GA was shown to have antitumor effects on LL-2 lung cancer cells transplanted in mice (15) and NCI-H460 human lung cancer cells in vitro and in vivo (10). However, there is no study to show that GA affected A375.S2 human melanoma cells. Therefore, it is important to clarify the in vitro anti-skin cancer effect of GA and also to find the possible signaling pathway. In the present study, the effects of GA were investigated in the growth and 
apoptotic cells death of A375.S2 human melanoma cells in vitro.

\section{Materials and methods}

Chemicals and reagents. Gallic acid (GA), dimethyl sulfoxide (DMSO), propidium iodide (PI), RNase A, and Triton X-100 were obtained from Sigma Chemical Co. (St. Louis, MO, USA). RPMI-1640, penicillin-streptomycin, trypsin-EDTA, fetal bovine serum (FBS) and L-glutamine were obtained from Gibco $^{\circledR} /$ Invitrogen (Carlsbad, CA, USA). DCFH-DA, Fluo-3/ $\mathrm{AM}$ and $\mathrm{DiOC}_{6}$ were purchased from Molecular Probes/ Invitrogen (Eugene, OR, USA). Caspase-3, caspase- 8 and caspase- 9 activity assay kits were from OncoImmunin, Inc. (Gaithersburg, MD, USA). Caspase-3 inhibitor (z-DEVDfmk), caspase-8 inhibitor (z-IETD-fmk) and caspase-9 inhibitor (z-LEHD-fmk) were obtained from R\&D Systems (Minneapolis, MN, USA).

Malignant human melanoma cell line (A375.S2). The A375.S2 cell line was purchased from the Food Industry Research and Development Institute (Hsinchu, Taiwan). About $1 \times 10^{6}$ cells/ml were cultured in $75 \mathrm{~cm}^{2}$ tissue culture flasks with minimum essential media (MEM) supplemented with $10 \%$ fetal bovine serum, penicillin-streptomycin $(100 \mathrm{U} / \mathrm{ml}$ penicillin and $100 \mu \mathrm{g} / \mathrm{ml}$ streptomycin) and $2 \mathrm{mM}$ L-glutamine and grown at $37^{\circ} \mathrm{C}$ in humidified $5 \% \mathrm{CO}_{2}$ and $95 \%$ air.

Assessment of cell viability. Approximately $2 \times 10^{5}$ cells/well of A375.S2 cells were plated onto 12-well plates and incubated at $37^{\circ} \mathrm{C}$ for 24 and $48 \mathrm{~h}$ before being treated with 0,50 , 100, 200 and $300 \mu \mathrm{M} \mathrm{GA}$ then incubated for 24 and $48 \mathrm{~h}$. A $0.5 \%$ of DMSO (solvent) was used for the control regimen. The cells were treated with 200 and $250 \mu \mathrm{M}$ GA for 0,12 , 24,48 and $72 \mathrm{~h}$. Cells $\left(1 \times 10^{5}\right.$ cells per sample) were centrifuged at $1000 \mathrm{x}$ g for $5 \mathrm{~min}$, cell pellets were dissolved with $0.5 \mathrm{ml}$ of PBS containing $5 \mu \mathrm{g} / \mathrm{ml}$ PI and viable cells were deter-mined by using FACSCalibur utilizing CellQuest software (Becton-Dickinson, San Jose, CA, USA) for determination of viable cells as previously described (14-16).

Determinations of sub-G1 (apoptosis) by flow cytometry. Approximately $2 \times 10^{5}$ cells/well of A375.S2 cells were grown in a 12-well plate for $24 \mathrm{~h}$ after $0,50,100,200$ and $300 \mu \mathrm{M}$ of GA were added and cells were incubated at $37^{\circ} \mathrm{C}, 5 \% \mathrm{CO}_{2}$ and $95 \%$ air for $48 \mathrm{~h}$. Cells from each treatment were isolated, then fixed with $70 \%$ ethanol at $4^{\circ} \mathrm{C}$ overnight and re-suspended in PBS containing $40 \mu \mathrm{g} / \mathrm{ml}$ PI and $0.1 \mathrm{mg} / \mathrm{ml}$ RNase and $0.1 \%$ Triton X-100 in dark room for $30 \mathrm{~min}$ at room temperature. Those cells were analyzed with a flow cytometer equipped with an argon ion laser at $488 \mathrm{~nm}$ wavelength. The cell cycle with sub-G1 was then determined and analyzed that was conducted with flow cytometry (BecktonDickinson) $(16,17)$.

4,6-diamidino-2-phenylindole dihydrochloride (DAPI) staining for apoptotic cells. A375.S2 cells at a density of $1 \times 10^{5}$ cells/well were plated onto 6 -well plates and treated with $\mathrm{GA}(0,50,100,250$ and $300 \mu \mathrm{M})$ and incubated for 24 and $48 \mathrm{~h}$ before cells from each treatment were isolated for
DAPI staining, as described previously $(14,16)$. After staining, the cells were examined and photographed using a fluorescence microscope (18).

Reactive oxygen species (ROS), intracellular $\mathrm{Ca}^{2+}$ release and mitochondrial membrane potential $\left(\Delta \Psi_{m}\right)$ determinations. A375.S2 cells at a density of $1 \times 10^{5}$ cells/well were plated onto 12-well plates and treated with $250 \mu \mathrm{M}$ GA for $0,0.5$, 1,3 and $6 \mathrm{~h}$ to changes in ROS, intracellular $\mathrm{Ca}^{2+}$ release and $0,12,24,48$ and $72 \mathrm{~h}$ for $\Delta \Psi_{m}$. Cells were harvested from each treatment, then re-suspended in $500 \mu 1$ of DCFH-DA $(10 \mu \mathrm{M})$ for $\operatorname{ROS}\left(\mathrm{H}_{2} \mathrm{O}_{2}\right)$ determination, re-suspended in $500 \mu 1$ of Fluo-3/AM $(2.5 \mu \mathrm{g} / \mathrm{ml})$ for intracellular $\mathrm{Ca}^{2+}$ concentrations and suspended in $500 \mu 1$ of $\mathrm{DiOC}_{6}(4 \mu \mathrm{mol} / \mathrm{l})$ for $\Delta \Psi_{m}$, incubated at $37^{\circ} \mathrm{C}$ for $30 \mathrm{~min}$ and analyzed by flow cytometry (19-21). Cells were pretreated with $15 \mathrm{mM}$ NAC for $3 \mathrm{~h}$ then treated with $250 \mu \mathrm{M}$ GA for $24 \mathrm{~h}$. The $\%$ of cell viability was determined by flow cytometry. All fluorescence intensities were obtained from the mean intensity of the histogram constructed from 10,000 cells.

Caspase-3, -8 and -9 activity determinations by flow cytometry. A375.S2 cells at a density of $1 \times 10^{5}$ cells/well were plated onto 12-well plates, pre-treated with or without caspase inhibitors [caspase-3 inhibitor (15 $\mu \mathrm{M}$ z-DEVDfmk), caspase-8 inhibitor (15 $\mu \mathrm{M}$ z-IETD-fmk) and caspase-9 inhibitor $(15 \mu \mathrm{M} \mathrm{z}$-LEHD-fmk)] for $3 \mathrm{~h}$ and then treated with $250 \mu \mathrm{M}$ GA for $24 \mathrm{~h}$ or with $250 \mu \mathrm{M}$ for $0,12,24,48$ and $72 \mathrm{~h}$. Cells were harvested by centrifugation, and the cell pellets were added $50 \mu \mathrm{l}$ of $10 \mu \mathrm{M}$ caspase- $3,-8$ and -9 substrate solution, PhiPhiLux ${ }^{\circledR}-\mathrm{G}_{1} \mathrm{D}_{2}$ for caspase-3, CaspaLux ${ }^{\circledR}$ 8- $\mathrm{L}_{1} \mathrm{D}_{2}$ for caspase- 8 and CaspaLux $9-\mathrm{M}_{1} \mathrm{D}_{2}$ for caspase-9. The samples were incubated at $37^{\circ} \mathrm{C}$ for 60 min before flow cytometric analysis. Caspase- $3,-8$ and -9 activities were detectable in the FL-1 channel (a BD instrument with emission at $525 \mathrm{~nm})(18,22)$.

Apoptotic-associated proteins examined by Western blotting. A total of $1 \times 10^{6} \mathrm{~A} 375 . \mathrm{S} 2$ cells $/ \mathrm{ml}$ cells were treated with $250 \mu \mathrm{M}$ GA for $0,12,24$ and $48 \mathrm{~h}$. Cells were harvested from each treatment by centrifugation for the total protein determination for Western blotting. The protein levels of Bcl-2, Bid, tBid, Bax, cytochrome c, caspase-9 and caspase-3, Fas, FasL, caspase-8, GRP78, GADD153 and caspase-4 were examined by using sodium dodecylsulfate polyacrylamide gel electrophoresis (SDS-PAGE) and Western blotting as described previously $(23,24)$.

Real-time PCR of caspase -8, Endo G and AIF. Total RNA was extracted from the A375.S2 cells after treatment with $250 \mu \mathrm{M}$ GA for 24 and $48 \mathrm{~h}$, using the Qiagen RNeasy Mini Kit as described previously (16). RNA samples were reversetranscribed for $30 \mathrm{~min}$ at $42^{\circ} \mathrm{C}$ with the High Capacity cDNA Reverse Transcription Kit (Applied Biosystems). Quantitative PCR was performed using the following conditions: $2 \mathrm{~min}$ at $50^{\circ} \mathrm{C}, 10 \mathrm{~min}$ at $95^{\circ} \mathrm{C}$, and 40 cycles at $15 \mathrm{sec}$ at $95^{\circ} \mathrm{C}$, $1 \mathrm{~min}$ at $60^{\circ} \mathrm{C}$ using $1 \mu 1$ of the cDNA reverse-transcribed as described above, 2X SYBR-Green PCR Master Mix (Applied Biosystems) and $200 \mathrm{nM}$ of forward (F) and reverse primers 
A

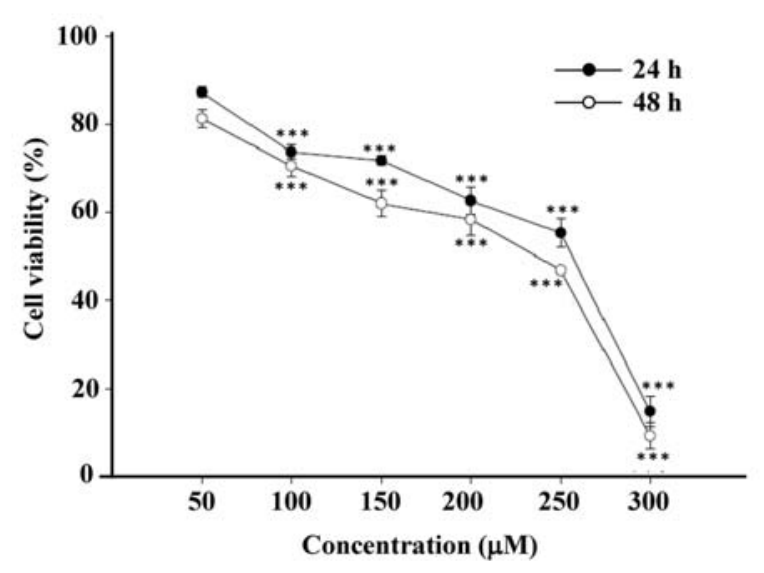

B

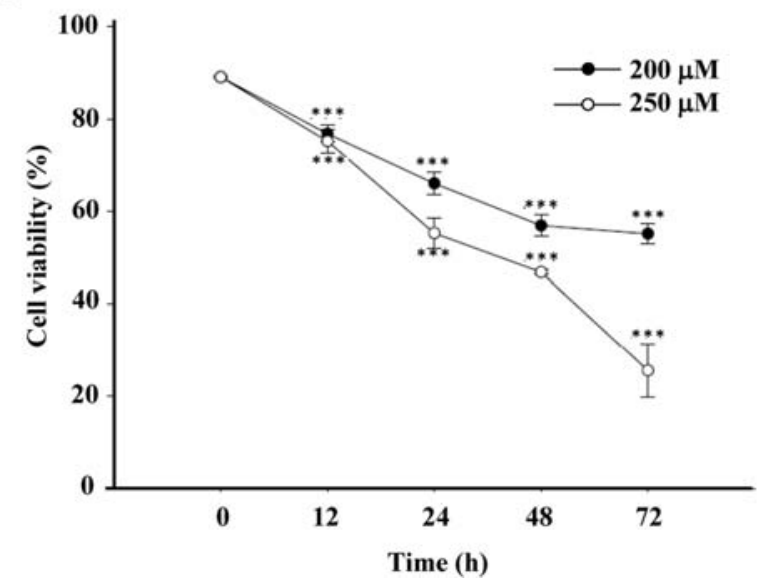

Figure 1. The effects of GA on the percentage of viable A375.S2 cells. A375.S2 cells were plated onto MEM + 10\% FBS with 0, 50, 100, 200 and 300 $\mu$ M GA for 24 and $48 \mathrm{~h}$ or after 200 or $250 \mu \mathrm{M}$ of GA treatment for 12, 24, 48 and $72 \mathrm{~h}$. Total percentage of viable cells were determined in dose- and timedependent response by flow cytometry (A and B) as described in Materials and methods. Each point is mean \pm S.D. of three experiments, ${ }^{*} \mathrm{p}<0.05,{ }^{* *} \mathrm{p}<0.01$, and ${ }^{* * *} \mathrm{p}<0.001$ were significantly different from the control.

(R): caspase-8-F: GGATGGCCACTGTGAATAACTG; caspase-8-R: TCGAGGACATCGCTCTCTCA; Endo G-F: GTACCAGGTCATCGGCAAGAA, Endo G-R: CGTAGGT GCGGAGCTCAATT; AIF-F: GGGAGGACTACGGCAAA GGT, AIF-R: CTTCCTTGCTATTGGCATTCG, GAPDH-F: ACACCCACTCCTCCACCTTT; GAPDH-R: TAGCCAAA TTCGTTGTCATACC. Each assay was run on an Applied Biosystems 7300 real-time PCR system in triplicate, and expression fold-changes were derived using the comparative $\mathrm{C}_{\mathrm{T}}$ method (16).

Immunofluorescence staining and confocal laser scanning microscopy. A375.S2 cells $\left(5 \times 10^{4}\right.$ cells/well) were placed on 4-well chamber slides before being treated with $250 \mu \mathrm{M}$ of GA for $24 \mathrm{~h}$. Then cells were fixed in $3 \%$ formaldehyde in PBS for $15 \mathrm{~min}$, permeabilized with $0.1 \%$ Triton X-100 in PBS for $1 \mathrm{~h}$ with blocking of non-specific binding sites using $2 \%$ BSA as described previously (25). Fixed cells were stained with primary antibodies to cytochrome c, GADD153 and GRP78 (1:100 dilution) overnight and then stained with secondary antibody (FITC-conjugated goat anti-mouse IgG at 1:100 dilution) (green fluorescence), followed by mitochondria and nuclei counterstaining which were individual with MitoTracker ${ }^{\circledR}$ Red CMXRos and PI (Molecular Probes/ Invitrogen Corp.) (red fluorescence). Photomicrographs were obtained using a Leica TCS SP2 confocal spectral microscope (25).

Statistical analyses. The statistical differences between the GA-treated and control samples were calculated by Student's t-test. A value of $\mathrm{p}<0.05, \mathrm{p}<0.01$, or $\mathrm{p}<0.001$ was considered significant. The results from the in vitro studies are representative of at least two or three independent experiments. The quantitative data are shown as mean \pm SD.

\section{Results}

Effects of GA on the percentage of cell death in A375.S2 cells. For examining the biological effects of GA, A375.S2 cells were treated with $0,50,100,200$ and $300 \mu \mathrm{M}$ of GA for 24 and $48 \mathrm{~h}$, and cell death was determined. GA caused cell death (Fig. 1A and B) at concentrations of $\geq 50 \mu \mathrm{M}$ which was dose-dependent. Based on these results, we selected the dose of $250 \mu \mathrm{M}$ GA to assess whether the growth-inhibitory and cell death effects of GA are accompanied by its effect on apoptotic cell death.

Effects of GA sub-G1 (apoptosis) of A375.S2 cells. GA induced significant cell cycle arrest at 50,100, 200, 250 and $300 \mu \mathrm{M}$ after incubation for $48 \mathrm{~h}$ (Fig. 2A and B). Compared with DMSO controls, GA at $50 \mu \mathrm{M}$ caused an arrest at G0-G1 $(61.85 \pm 1.93 \%$ versus $77.01 \pm 2.29 \%, \mathrm{p}<0.001)$ phases. $\mathrm{GA}$ at concentrations of $200 \mu \mathrm{M}$ for $48 \mathrm{~h}$ caused significant apoptotic cell death $(3.62 \pm 0.21 \%$ versus $18.79 \pm 4.44 \%$, $\mathrm{p}<0.001$ ) (Fig. 2A and B).

DAPI staining for examining GA-induced apoptotic cell death in A375.S2 cells. GA induced apoptosis in A375.S2 cells, and further support for the role of apoptosis is that DAPI staining assays revealed apoptotic cells in GA-treated A375.S2 cells in 24 and $48 \mathrm{~h}$ (Fig. 3A and B) compared with intact control cells and this effect was dose-dependent.

$G A$ affected the levels of reactive oxygen species (ROS) and intracellular $\mathrm{Ca}^{2+}$ and mitochondria membrane potential $\left(\Delta \Psi_{m}\right)$ in A375.S2 cells. To further examine whether GAinduced apoptosis in A375.S2 cells is due to the effects of ROS, intracellular $\mathrm{Ca}^{2+}$ and $\Delta \Psi_{m}$, A375.S2 cells were incubated with $250 \mu \mathrm{M}$ GA for various time periods. ROS and $\mathrm{Ca}^{2+}$ production and $\Delta \Psi_{m}$ were measured by flow cytometric assay. The data demonstrated that GA promoted ROS and intracellular $\mathrm{Ca}^{2+}$ productions in a time-dependent manner (Fig. 4A and B). The results also showed that GA promoted the loss of $\Delta \Psi_{m}$ in A375.S2 cells and this effect also is time-dependent (Fig. 4C). Cells were pretreated with an antioxidant $\mathrm{N}$-acetyl cysteine (NAC), and then exposure to GA led to increase the \% of cell viability (Fig. 4D). 
A
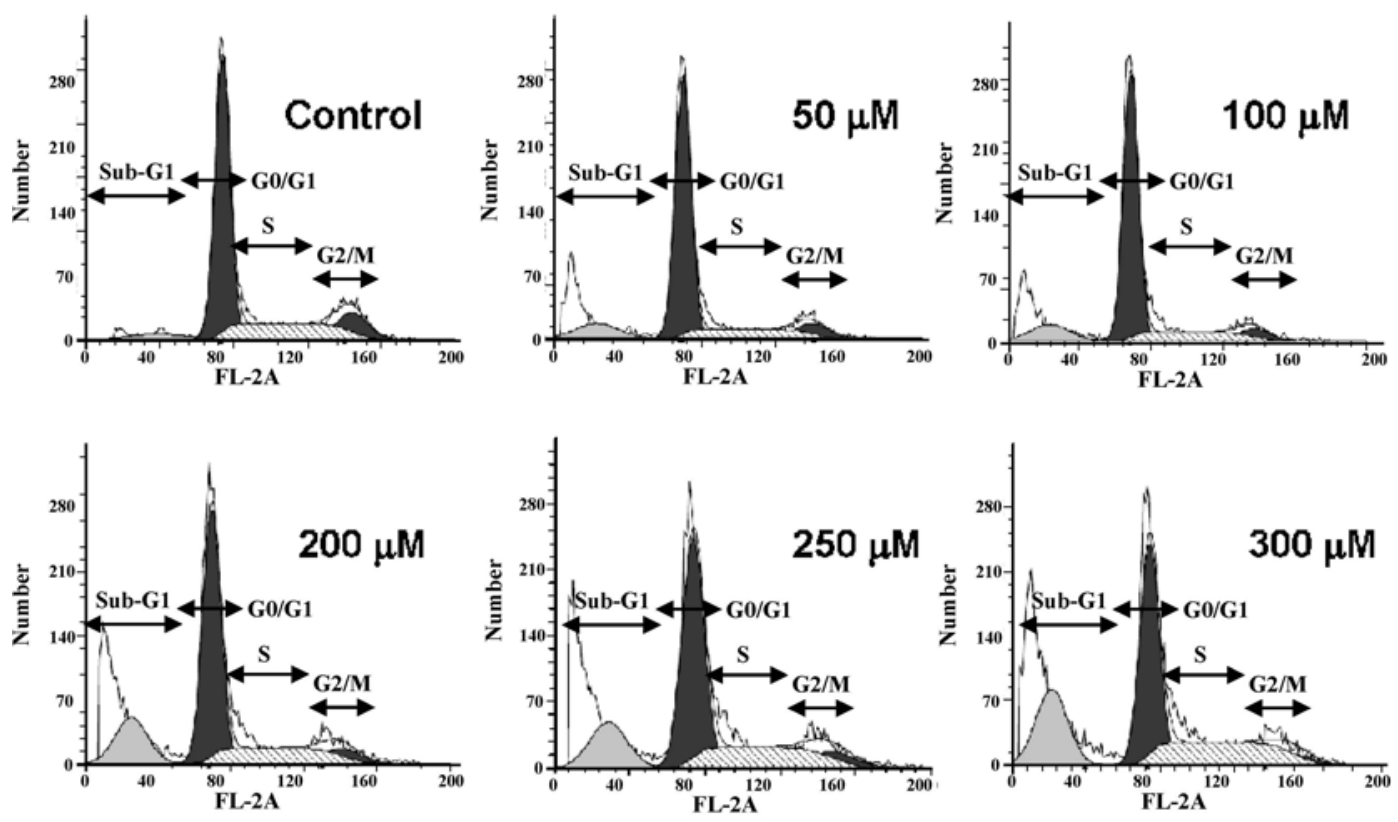

B

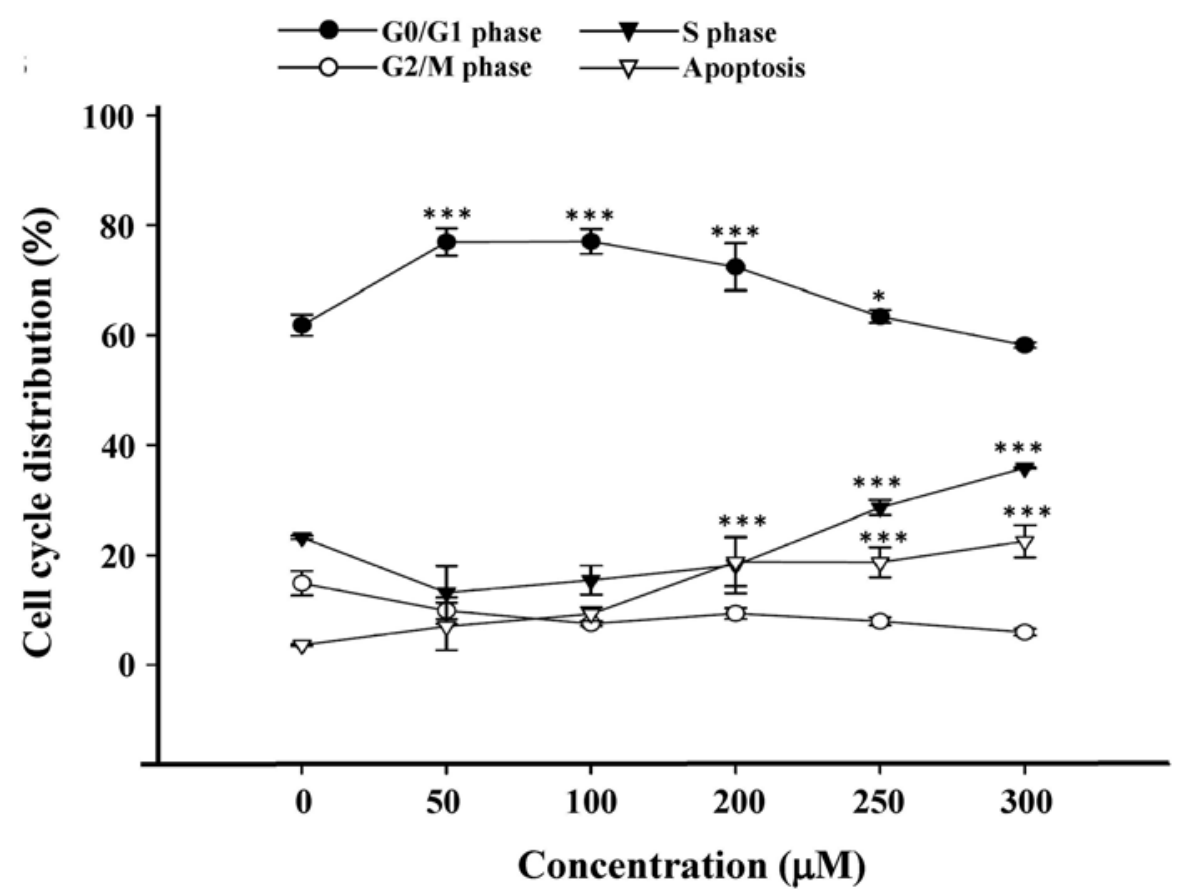

Figure 2. The effects of GA on sub-G1 group of A375.S2 cells. A375.S2 cells were plated in MEM + 10\% FBS with 0, 50, 100, 200, 250 and 300 $\mu$ M GA for $48 \mathrm{~h}$ and the cells were analyzed for cell cycle (A, representative profiles; B, the percentage of cells in phase) by flow cytometry. Each point is mean \pm S.D. of three experiments.

GA activated caspase-3, -8 and -9 in A375.S2 cells. A375.S2 cells were pre-treated with or without inhibitors of caspase-3 -8 and -9 , and then treated with GA. Cells were harvested for examining the activation of caspase- $3,-8$ and -9 and the percentage of viable cells after caspase inhibitors (z-DEVDfmk, z-IETD-fmk and z-LEHD-fmk, respectively) pretreatment. Data in Fig. 5A, B and C indicate that GA promoted activation of caspase- $3,-8$ and -9 in A375.S2 cells and these effects are time-dependent. Fig. 5D indicates that caspase inhibitors pretreatment led to increase the percentage of viable A375.S2 cells. These effects also showed that GAinduced apoptosis in A375.S2 cells was via caspase cascadedependent pathway.

GA affects apoptotic-associated proteins in A375.S2 cells. In order to further examine whether GA-induced apoptosis 
A
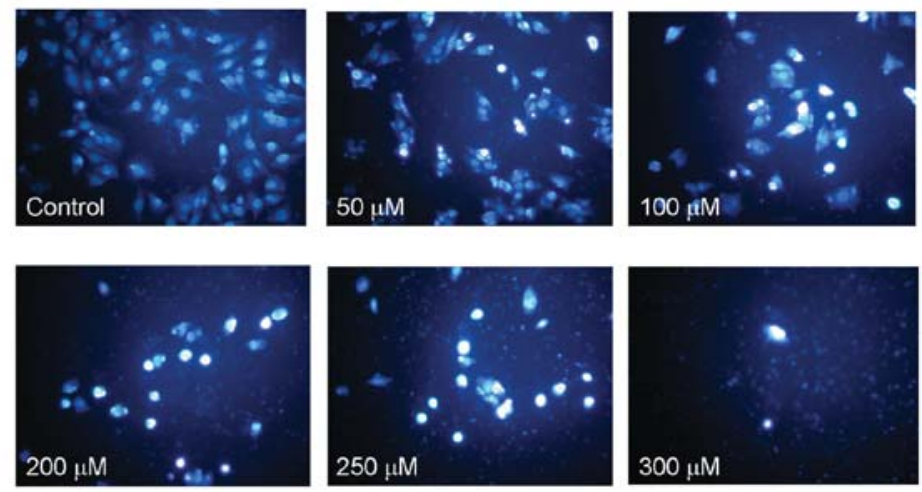

B
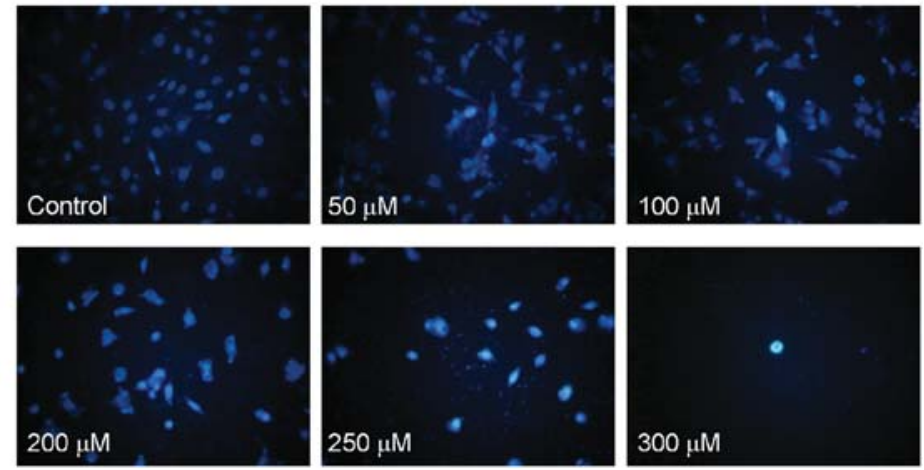

Figure 3. GA-induced apoptosis in A375.S2 cells. Cells were incubated with 0, 50, 100, 250 and $300 \mu \mathrm{M} \mathrm{GA}$ for 24 (A) and 48 h (B). Apoptotic cells were determined by DAPI staining and fluorescence microscopy as described in Materials and methods.
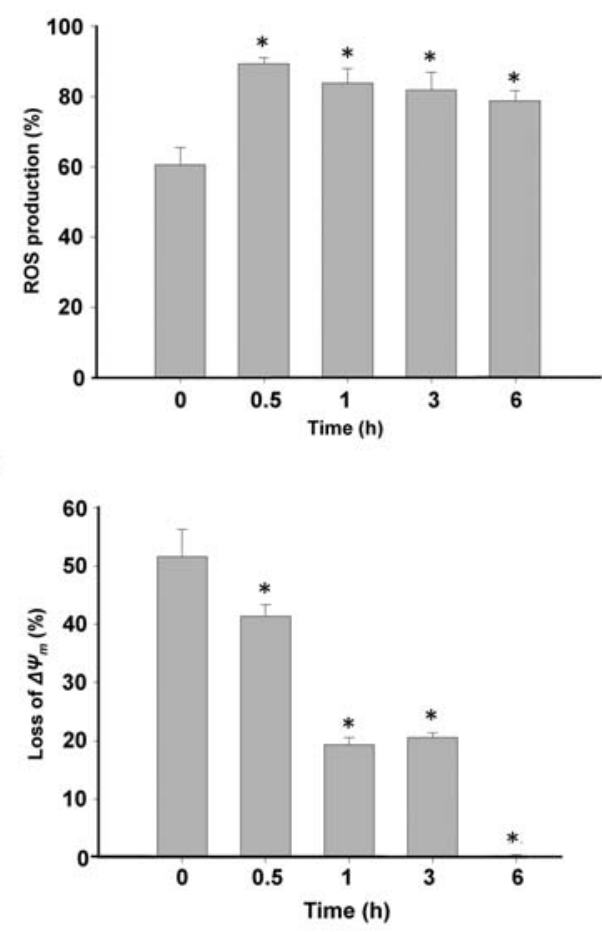

B
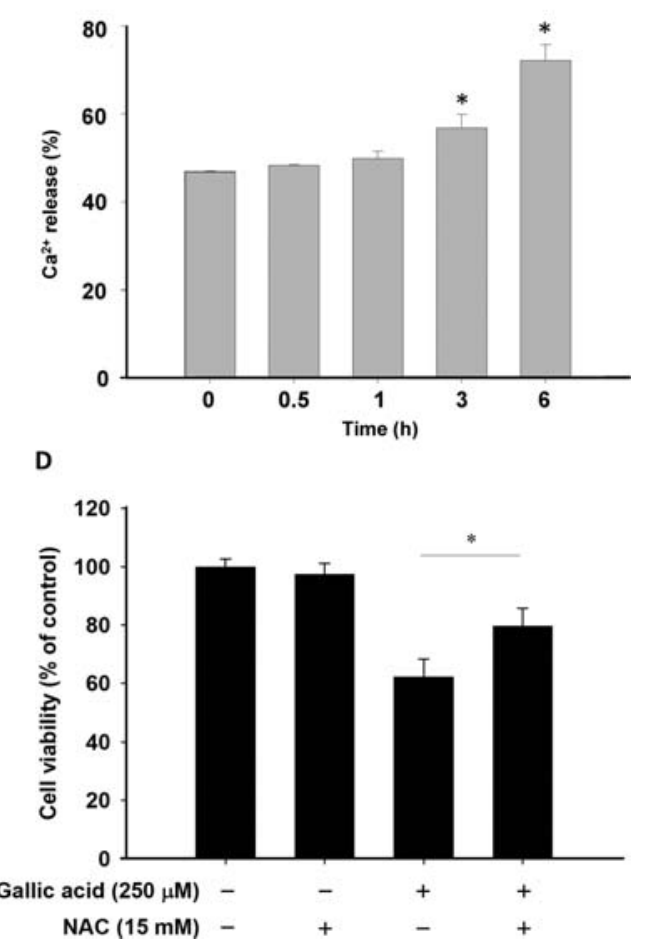

Figure 4. GA affects the levels of reactive oxygen species (ROS) and intracellular $\mathrm{Ca}^{2+}$ and mitochondria membrane potential $\left(\Delta \Psi_{m}\right)$ in A375.S2 cells. Cells were incubated with $250 \mu \mathrm{M} \mathrm{GA}$ for various time periods, before stained with DCFH-DA (2,7-dichlorodihydrofluorescein diacetate) for ROS level determination (A), stained by Fluo-3/AM for the intracellular $\mathrm{Ca}^{2+}$ level determination (B), and stained with $\mathrm{DiOC}_{6}$ for the $\Delta \Psi_{m}$ level determination (C) or cells were pre-treated with NAC and then the cell viability was determined (D) by flow cytometric analysis as described in Materials and methods. Each experiment was done with triple sets. ${ }^{*} \mathrm{p}<0.05$ was significantly different from the control. 
A

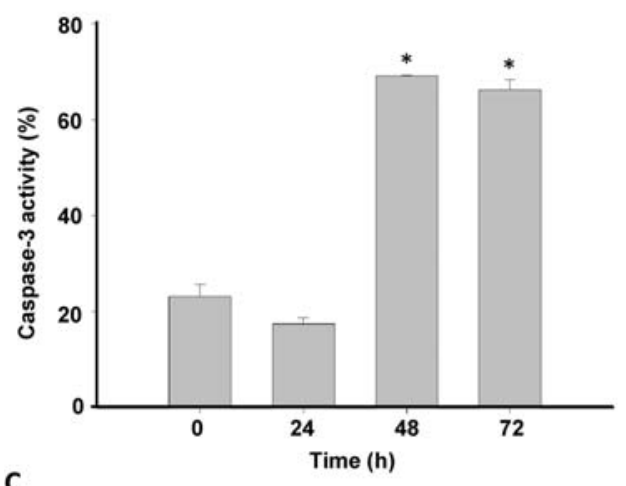

C

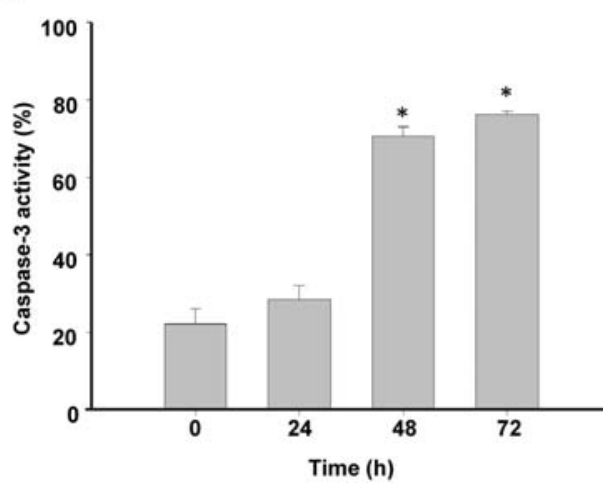

B
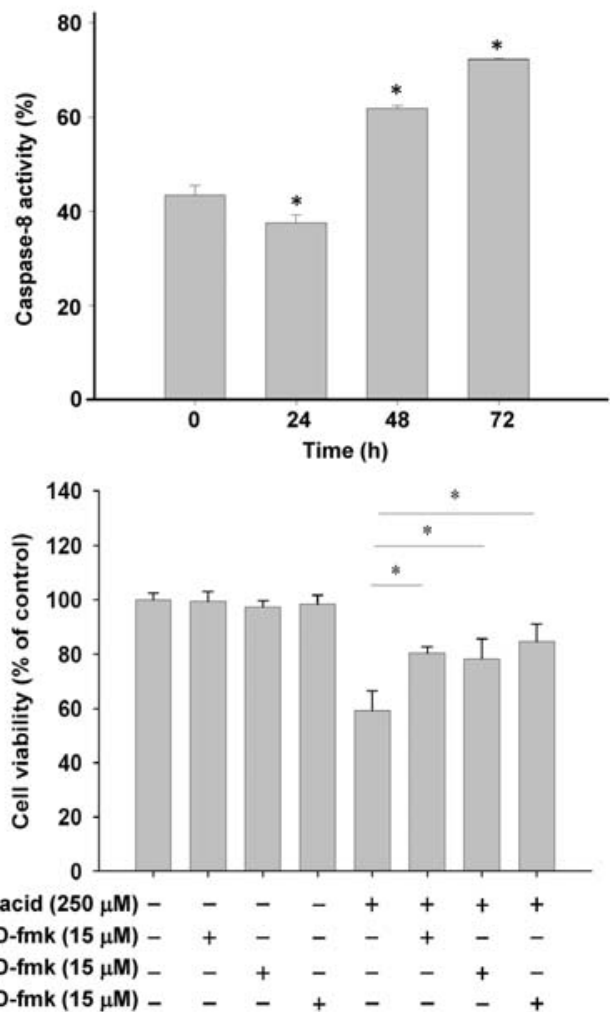

Figure 5. GA affects the activities of caspase-3, -8 and -9 of A375.S2 cells. Cells were plated onto 12-well plate in MEM + 10\% FBS which were preincubated with or without inhibitors and then with $250 \mu \mathrm{M}$ GA for various time periods. Cells were harvested from each sample for caspase-3 (A), -8 (B) and -9 (C) and for percentage of viable cells (D) were measured as described in Materials and methods. Each experiment was done with triple sets. "p $<0.05$ was significantly different from the control.

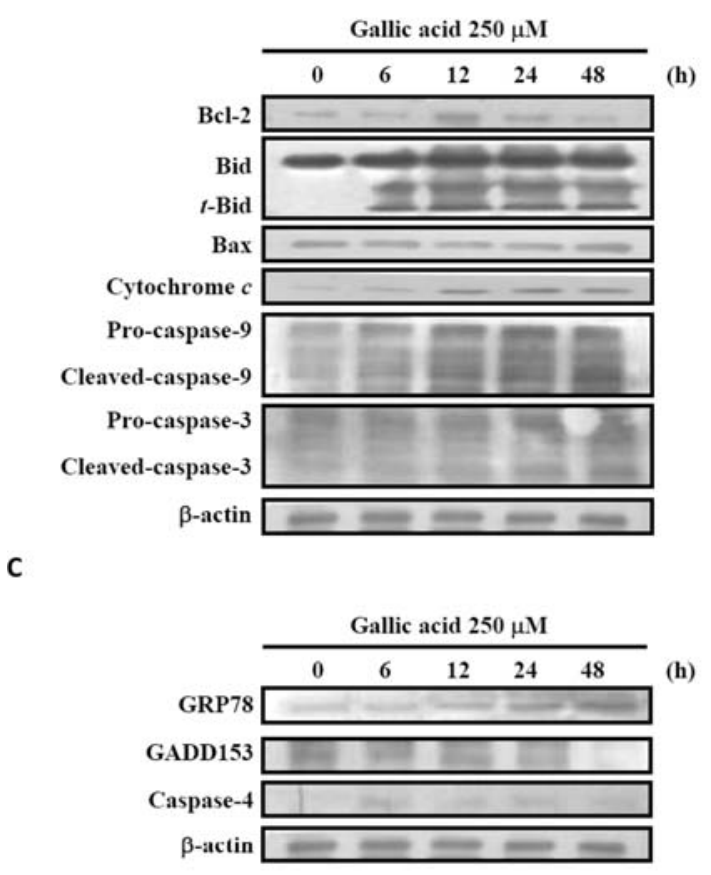

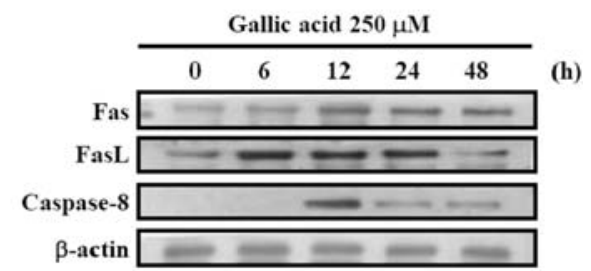

D

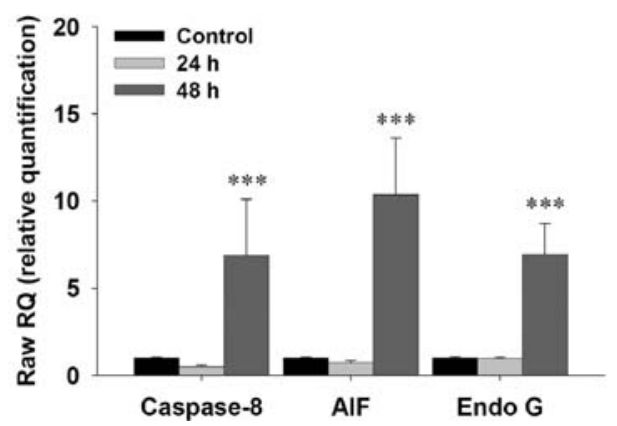

Figure 6. GA affects the apoptotic relative proteins and gene expression in A375.S2 cells. A total of 5x105 A375.S2 cells/ml were treated with 250 $\mu \mathrm{M}$ GA for $0,6,12,24$ and $48 \mathrm{~h}$. Cells were harvested from each sample and associated proteins were measured by Western blotting. The protein levels of Bcl-2, Bid, t-Bid, Bax, cytochrome c, caspase-9 and caspase-3 (A), Fas, FasL and caspase-8 (B), GRP78, GADD153 and caspase-4 (C) expressions were examined by using SDS-PAGE gel electrophoresis and Western blotting as described in Materials and methods. The total RNA was extracted from A375.S2 cells after exposure to $250 \mu \mathrm{M}$ GA for 0,24 and $48 \mathrm{~h}$ and RNA samples were reverse-transcribed cDNA then for real-time PCR. The ratios of caspase - 8, Endo $G$ and AIF mRNA/GAPDH are presented in panel (D). Data represent mean \pm S.D. of three experiments. ${ }^{* * *}$ p $<0.001$, significantly different compared with 0 h GA treatment. 
A

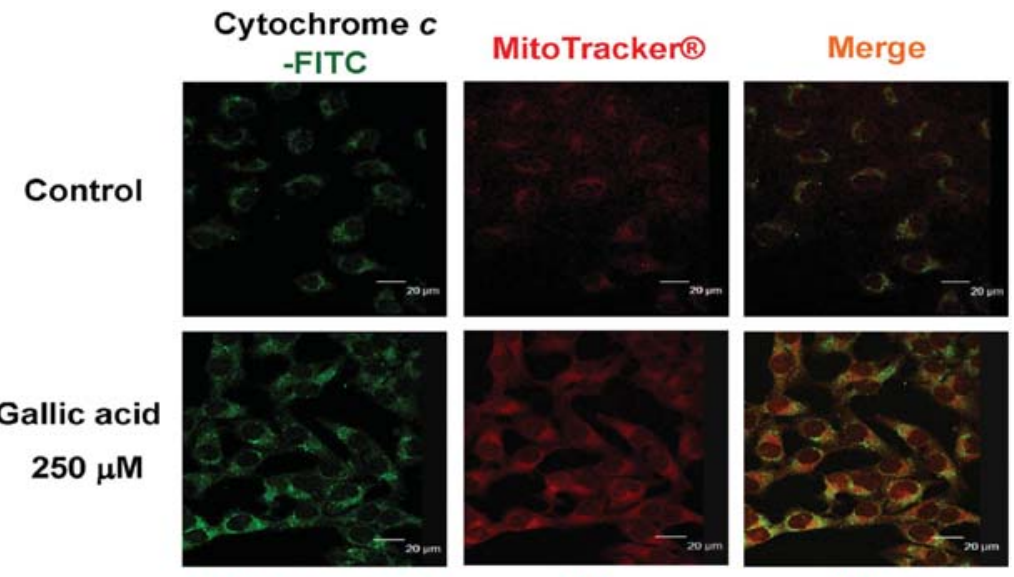

B

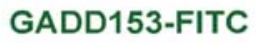

PI

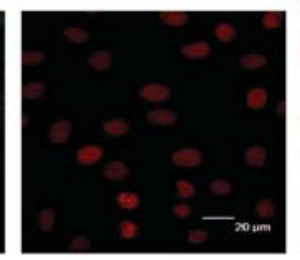

Merge
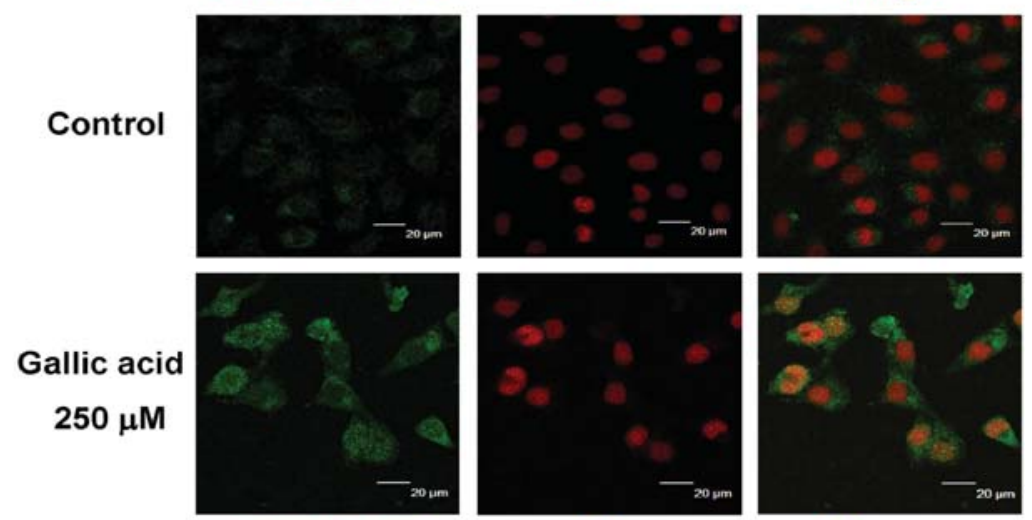

C

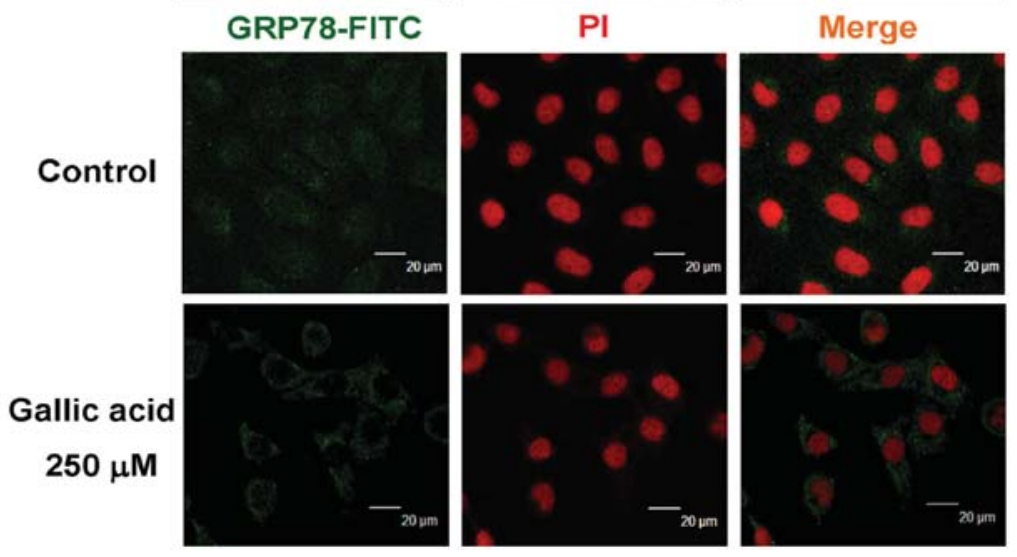

Figure 7. GA stimulates the translocations of apoptotic-associated proteins. A375.S2 cells (5x104 cells/well) were plated on 4-well chamber slides then treated with or without $250 \mu \mathrm{M}$ GA for $24 \mathrm{~h}$ before they were stained by antibodies as described in Material and methods. These results from confocal laser microscopic systems are shown in (A-C). (A) cytochrome c; (B) GADD153; (C) GRP78.

affected the associated protein levels in A375.S2 cells, cells were treated with GA for various time periods and examined by Western blotting. The results are presented in Fig. 6A, B and $\mathrm{C}$ indicated that GA-stimulated levels of Bax, cytochrome c, and active form of caspase-9 and -3 (Fig. 6A), Fas, FasL and active form of caspase-8 (Fig. 6B), GADD153 and GRP78 (Fig. 6C), but GA decreased levels of Bcl-2 (Fig. 6A) in A375.S2 cells. Based on the real-time PCR result (Fig. 6D) indicated that GA promoted the gene expression of mRNA caspase-8, AIF and Endo $G$ at 48 h of treatment.

GA stimulates apoptotic relative proteins and their translocations. A375.S2 cells were exposed to $250 \mu \mathrm{M}$ GA for $24 \mathrm{~h}$ before being stained by primary antibodies of cytychrome $\mathrm{c}$,
GADD153 and GRP78. These results from confocal laser microscopic systems indicated that cytochrome c (Fig. 7A), GADD153 (Fig. 7B) and GRP78 (Fig. 7C) were elevated in A375.S2 cells after GA treatment. There results also show that GA promoted cytochrome c release from mitochondria then translocated to cytosol, and GADD153 and GRP78 translocated in the nuclei, when compared to the control.

\section{Discussion}

Numerous studies have established that GA inhibits cell growth and induces apoptosis in many cancer cell lines $(10,26,27)$. It was also reported that GA induces apoptosis in esophageal cancer cells (TE-2) but not in non-cancerous cells 


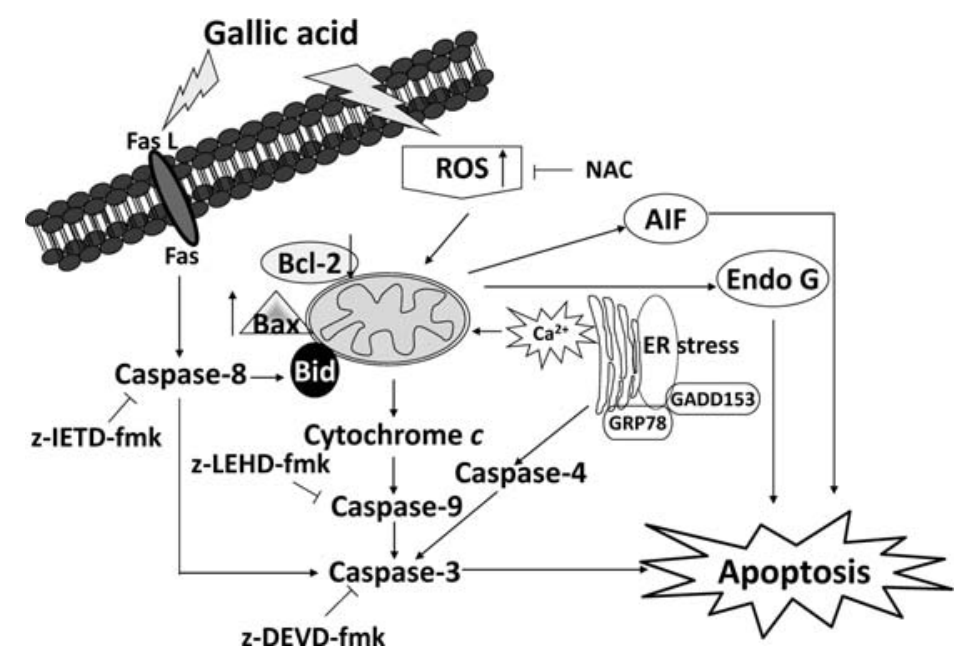

Figure 8. The proposed signaling pathways of GA-induced apoptosis in A375.S2 human melanoma cells.

(CHEK-1) (27). In the present study, we found that GA caused a significant decrease $(\mathrm{p}<0.05)$ in the cell population growth of A375.S2 at 48 and $72 \mathrm{~h}$ (Fig. 1A and B). Apoptotic cells are characterized by distinct morphological features including cell shrinkage, chromatin condensation, membrane blebbing and formation of apoptotic bodies (Fig. 3). Although many experiments have shown that GA induces apoptosis in human cancer cell lines, the molecular mechanism of apoptosis induction in A375.S2 melanoma cells remains unclear. The present study further investigated the effect of GA on the intrinsic pathway of apoptosis in A375.S2 cancer cells.

It is well-known that apoptosis (programmed cell death) can be activated through two main pathways such as the mitochondria-dependent pathway (intrinsic pathway) and the death receptor-dependent pathway (extrinsic pathway) (28). Fas and its receptor Fas ligand (FasL) and caspase- 8 are part of an important cellular pathway regulating the induction of apoptosis in diverse cell types and tissues (29). Here, our data indicated that treatment of GA markedly activated Fas, FasL and caspase- 8 proteins (Fig. 6B). The mitochondriadependent pathway and death receptor-dependent pathway are both regulated by $\mathrm{Bcl}-2$ family proteins. $\mathrm{Bcl}-2$ family proteins are involved in apoptosis including the pro-apoptotic proteins Bax, Bak, Bad and Bcl-XS and the anti-apoptotic proteins Bcl-2, Bcl-XL and Mcl-1 (30). In the present study, the results from Western blotting indicated that GA promoted Bax levels but decreased Bcl-2 levels (Fig. 6B). The ratio of $\mathrm{Bax} / \mathrm{Bcl}-2$ plays an important role in determining whether cells will undergo apoptosis under experimental conditions that promote cell death (30). The ratio of Bax/Bcl-2 affects the levels of mitochondrial membrane potential in cells after exposure to inducer of apoptosis (30). Other investigators (31) also reported that mitochondrial release of cytochrome c can be controlled by the ratio of $\mathrm{Bax} / \mathrm{Bcl}-2$ proteins and may be activated by proteolytic cleavage and heterodimerization. The results from Western blotting indicated that the upregulation of Bax and the down-regulation of Bcl-2 could be another molecular mechanism through which GA induced apoptosis in A375.S2 cells.

The results also showed that GA induced the decrease of $\Delta \Psi_{m}$ in A375.S2 cells. The disruption of the $\Delta \Psi_{m}$ is recog- nized to be an early stage of apoptosis, where release of cytochrome $\mathrm{c}$ from the mitochondria is followed by caspase-3/ caspase-9 cascade activation (32). Apoptosis can also be divided into caspase-dependent and caspase-independent pathways. The caspase- 3 plays a pivotal role in the terminal execution phase of apoptosis (33). The results from flow cytometric assays indicated that GA promoted the activations of caspase-8, -9 and -3 in A375.S2 cells (Fig. 5A, B and C). The results also showed caspase- 3 and -8 inhibitors significantly reduced the inhibition of cell viability caused by GA in A375.S2 cells (Fig. 5D). Furthermore, the pretreatment with the caspase- 8 and -3 inhibitors inhibited GA-induced apoptosis, suggesting that GA-induced apoptosis also involves caspase-8- and -3-mediated mechanisms. Caspase-independent pathway was involved in dysfunction of mitochondria leding to release of AIF and Endo G from mitochondria then to apoptosis $(34,35)$. Our results from the immuno-fluorescence staining also showed that GA promoted the protein levels of AIF and Endo G in A375.S2 cells, suggesting that GA-induced apoptosis also involves caspase-independent mechanisms. Furthermore, in order to examine whether GA promoted the protein levels of caspase-3, AIF and Endo G through the effects of mRNA levels of caspase-3, AIF and Endo G, realtime PCR was used for examination of mRNA expression and results indicated that GA promoted the levels of mRNA expression in caspase-3, AIF and Endo G.

In conclusion, we propose the signaling pathway of GAinduced apoptosis in A375.S2 cells as shown in Fig. 8. The flow chart shows that GA triggers apoptosis through the regulation of Fas/FasL, Bax and Bcl-2 and through activation of the caspase cascade (caspase-3, -8 and -9) or through the dysfunction of mitochondria leding to AIF and Endo G release causing apoptosis. These results provide a potential molecular mechanism for GA-induced apoptosis in A375.S2 cells.

\section{Acknowledgments}

This study was supported by grant CMU98-S-04 from China Medical University, Taichung, Taiwan. 


\section{References}

1. Girschik J, Fritschi L, Threlfall T and Slevin T: Deaths from non-melanoma skin cancer in Western Australia. Cancer Causes Control 19: 879-885, 2008.

2. Gava B, Zorzet S, Spessotto P, Cocchietto M and Sava G: Inhibition of B16 melanoma metastases with the ruthenium complex imidazolium trans-imidazoledimethylsulfoxidetetrachlororuthenate and down-regulation of tumor cell invasion. J Pharmacol Exp Ther 317: 284-291, 2006.

3. Hong WK and Sporn MB: Recent advances in chemoprevention of cancer. Science 278: 1073-1077, 1997.

4. Abou El Hassan MA, Braam SR and Kruyt FA: Paclitaxel and vincristine potentiate adenoviral oncolysis that is associated with cell cycle and apoptosis modulation, whereas they differentially affect the viral life cycle in non-small-cell lung cancer cells. Cancer Gene Ther 13: 1105-1114, 2006.

5. Fiuza SM, Gomes C, Teixeira LJ, et al: Phenolic acid derivatives with potential anticancer properties - a structure-activity relationship study. Part 1: Methyl, propyl and octyl esters of caffeic and gallic acids. Bioorg Med Chem 12: 3581-3589, 2004.

6. Grundhofer P, Niemetz R, Schilling G and Gross GG: Biosynthesis and subcellular distribution of hydrolyzable tannins. Phytochemistry 57: 915-927, 2001

7. Manna SK, Kuo MT and Aggarwal BB: Overexpression of gamma-glutamylcysteine synthetase suppresses tumor necrosis factor-induced apoptosis and activation of nuclear transcription factor-kappa B and activator protein-1. Oncogene 18: 4371-4382, 1999.

8. Klein $\mathrm{E}$ and Weber N: In vitro test for the effectiveness of antioxidants as inhibitors of thiyl radical-induced reactions with unsaturated fatty acids. J Agric Food Chem 49: 1224-1227, 2001.

9. Inoue M, Suzuki R, Koide T, Sakaguchi N, Ogihara Y and Yabu Y: Antioxidant, gallic acid, induces apoptosis in HL60RG cells. Biochem Biophys Res Commun 204: 898-904, 1994.

10. Ji BC, Hsu WH, Yang JS, et al: Gallic acid induces apoptosis via caspase-3 and mitochondrion-dependent pathways in vitro and suppresses lung xenograft tumor growth in vivo. J Agric Food Chem 57: 7596-7604, 2009.

11. Yoshioka K, Kataoka T, Hayashi T, Hasegawa M, Ishi Y and Hibasami H: Induction of apoptosis by gallic acid in human stomach cancer KATO III and colon adenocarcinoma colo 205 cell lines. Oncol Rep 7: 1221-1223, 2000.

12. Kang MK, Kang NJ, Jang YJ, Lee KW and Lee HJ: Gallic acid induces neuronal cell death through activation of c-jun Nterminal kinase and downregulation of Bcl-2. Ann NY Acad Sci 1171: 514-520, 2009.

13. Sakaguchi N, Inoue $M$ and Ogihara Y: Reactive oxygen species and intracellular $\mathrm{Ca}^{2+}$, common signals for apoptosis induced by gallic acid. Biochem Pharmacol 55: 1973-1981, 1998.

14. Ban JY, Nguyen HT, Lee HJ, et al: Neuroprotective properties of gallic acid from sanguisorbae radix on amyloid beta protein (25-35)-induced toxicity in cultured rat cortical neurons. Biol Pharm Bull 31: 149-153, 2008.

15. Kawada M, Ohno Y, Ri Y, et al: Anti-tumor effect of gallic acid on 11-2 lung cancer cells transplanted in mice. Anticancer Drugs 12: $847-852,2001$

16. Lin SS, Huang HP, Yang JS, et al: DNA damage and endoplasmic reticulum stress mediated curcumin-induced cell cycle arrest and apoptosis in human lung carcinoma A-549 cells through the activation caspases cascade- and mitochondrialdependent pathway. Cancer Lett 272: 77-90, 2008.
17. Li YC, Lin HJ, Yang JH, et al: Baicalein-induced apoptosis via endoplasmic reticulum stress through elevations of reactive oxygen species and mitochondria-dependent pathway in mouserat hybrid retina ganglion cells (N18). Neurochem Res 34: 418-429, 2009.

18. Yang JS, Chen GW, Hsia TC, et al: Diallyl disulfide induces apoptosis in human colon cancer cell line (colo 205) through the induction of reactive oxygen species, endoplasmic reticulum stress, caspases casade and mitochondrial-dependent pathways. Food Chem Toxicol 47: 171-179, 2009.

19. Kalbacova M, Vrbacky M, Drahota Z and Melkova Z: Comparison of the effect of mitochondrial inhibitors on mitochondrial membrane potential in two different cell lines using flow cytometry and spectrofluorometry. Cytometry A 52: 110-116, 2003.

20. Lu HF, Sue CC, Yu CS, Chen SC, Chen GW and Chung JG: Diallyl disulfide (DADS) induced apoptosis undergo caspase-3 activity in human bladder cancer T24 cells. Food Chem Toxicol 42: 1543-1552, 2004.

21. Park EK, Kwon KB, Park KI, Park BH and Jhee EC: Role of $\mathrm{Ca}(2+)$ in diallyl disulfide-induced apoptotic cell death of HCT-15 cells. Exp Mol Med 34: 250-257, 2002.

22. Wu PP, Kuo SC, Huang WW, et al: (-)-epigallocatechin gallate induced apoptosis in human adrenal cancer NCI-H295 cells through caspase-dependent and caspase-independent pathway. Anticancer Res 29: 1435-1442, 2009.

23. Hsiao YP, Huang HL, Lai WW, Chung JG and Yang JH: Antiproliferative effects of lactic acid via the induction of apoptosis and cell cycle arrest in a human keratinocyte cell line (HaCaT). J Dermatol Sci 54: 175-184, 2009.

24. Lin SS, Lai KC, Hsu SC, et al: Curcumin inhibits the migration and invasion of human A549 lung cancer cells through the inhibition of matrix metalloproteinase- 2 and -9 and vascular endothelial growth factor (VEGF). Cancer Lett 285: 127-133, 2009.

25. Chen JC, Lu KW, Tsai ML, et al: Gypenosides induced G0/G1 arrest via $\mathrm{CHk} 2$ and apoptosis through endoplasmic reticulum stress and mitochondria-dependent pathways in human tongue cancer SCC-4 cells. Oral Oncol 45: 273-283, 2009.

26. Hsu CL, Huang SL and Yen GC: Inhibitory effect of phenolic acids on the proliferation of 3T3-11 preadipocytes in relation to their antioxidant activity. J Agric Food Chem 54: 4191-4197, 2006.

27. Hsu CL, Lo WH and Yen GC: Gallic acid induces apoptosis in 3T3-11 pre-adipocytes via a Fas- and mitochondrial-mediated pathway. J Agric Food Chem 55: 7359-7365, 2007.

28. Thornberry NA, Rano TA, Peterson EP, et al: A combinatorial approach defines specificities of members of the caspase family and granzyme B. Functional relationships established for key mediators of apoptosis. J Biol Chem 272: 17907-17911, 1997.

29. Nagata $S$ and Golstein P: The Fas death factor. Science 267 : 1449-1456, 1995.

30. Merry DE and Korsmeyer SJ: Bcl-2 gene family in the nervous system. Annu Rev Neurosci 20: 245-267, 1997.

31. Cory S and Adams JM: The Bcl2 family: Regulators of the cellular life-or-death switch. Nat Rev Cancer 2: 647-656, 2002.

32. Green DR and Reed JC: Mitochondria and apoptosis. Science 281: 1309-1312, 1998

33. Thornberry NA and Lazebnik Y: Caspases: enemies within. Science 281: 1312-1316, 1998.

34. Hsu SC, Yang JS, Kuo CL, et al: Novel quinolone CHM-1 induces apoptosis and inhibits metastasis in a human osterogenic sarcoma cell line. J Orthop Res 27: 1637-1644, 2009.

35. Kitagawa K and Niikura Y: Caspase-independent mitotic death (CIMD). Cell Cycle 7: 1001-1005, 2008. 